\title{
Re-establishing apical patency after obturation with Gutta-percha and two novel calcium silicate-based sealers
}

\author{
Anastasia Agrafioti ${ }^{1}$, Anastasios D. Koursoumis ${ }^{1}$, Evangelos G. Kontakiotis ${ }^{1}$
}

Correspondence: Dr. Evangelos G. Kontakiotis

Email: ekontak@dent.uoa.gr
'Department of Endodontics, School of Dentistry, National and Kapodistrian University of Athens, Athens, Greece

\section{ABSTRACT}

Objective: Aim of the present study was to evaluate the retreatability and reestablishment of apical patency of two calcium silicate-based sealers, TotalFill BC Sealer (BCS) and mineral trioxide aggregate Fillapex (MTA F), versus AH Plus, when used in combination with Gutta-percha (GP). Materials and Methods: The canals of 54 single-rooted anterior teeth were instrumented and filled with GP/AH Plus (Group A), GP/MTA F (Group B), or GP/BCS (Group C) using continuous wave obturation technique. The groups were subdivided into subgroups with the master-GP cone placed to the working length (WL) or intentionally $2 \mathrm{~mm}$ short. The retreatment procedures were performed using ultrasonics, chloroform, rotary, and hand files. The ability to establish the patency and reach WL was determined as well as the time taken to reach WL was calculated in minutes. Furthermore, the samples were observed under a dental, optical microscope, after vertically splitting them. Results: The WL and patency were reestablished in $100 \%$ of specimens in all groups. The Mann-Whitney U-test indicated that there was a significant difference in the amount of time required to reach WL between the groups $(P<0.05)$ with group GP/BCS short of the WL showing the most amount of time to be retreated. Conclusion: The novel calcium silicate-based sealers are negotiable under simple root canal anatomy. However, the conventional retreatment techniques are not able to fully remove them.

Key words: Bioceramics, calcium silicate, mineral trioxide aggregate, retreatment, root canal sealer

\section{INTRODUCTION}

Endodontic treatment is not always successful and periradicular inflammatory lesions might persist or develop postoperatively. Nonsurgical endodontic retreatment is necessary when the posttreatment disease is diagnosed. ${ }^{[1]}$ The aim of endodontic retreatment is the complete removal of the solid obturating core material and its associated sealer, in order to regain access and patency to the apical foramen for an effective cleaning and shaping of the root canal system. $\cdot^{[2]}$

Gutta-percha (GP) core material in combination with sealers is the most commonly used root canal filling material. ${ }^{[3]}$ Endodontic sealers can be categorized based on their composition or chemical structure on many different groups such as zinc oxide-eugenol, calcium hydroxide, glass ionomer, resin, or silicon. ${ }^{[4]}$ More recently, manufacturers have developed innovative contemporary endodontic sealers with calcium silicate-based technology such as mineral trioxide aggregate (MTA)-based sealers and bioceramic-based sealers. ${ }^{[5,6]}$ According to the current literature, these materials are biocompatible, induce biomineralization, offer antimicrobial activity, achieve better bond strength to dentin than conventional sealers, and exhibit sealing ability on equal terms with epoxy resin-based sealers. ${ }^{[6-12]}$

This is an open access article distributed under the terms of the Creative Commons Attribution-NonCommercial-ShareAlike 3.0 License, which allows others to remix, tweak, and build upon the work non-commercially, as long as the author is credited and the new creations are licensed under the identical terms.

For reprints contact: reprints@medknow.com

How to cite this article: Agrafioti A, Koursoumis AD, Kontakiotis EG. Re-establishing apical patency after obturation with Gutta-percha and two novel calcium silicate-based sealers. Eur J Dent 2015;9:457-61.

DOI: $10.4103 / 1305-7456.172625$ 
MTA Fillapex (MTA-F) (Angelus Soluções Odontológicas, Londrina, PR, Brazil) is one of the several-based sealers that has been recently introduced to the endodontic community. According to the manufacturer reports, the sealer is a 2-paste system that contains $40 \%$ MTA, salicylate resin, natural resin, bismuth, and silica. ${ }^{[13]}$ EndoSequence BC Sealer (BCS) (Brasseler, Savannah, GA, USA), also known as TotalFill BCS in Europe (FKG Dentaire SA, La Chaux-de-Fonds, Switzerland), is the major representative of bioceramic-based sealers. Its inorganic components include zirconium oxide, calcium silicates, calcium phosphate monobasic, calcium hydroxide, filler, and water-free thickening agents. BCS is a premixed ready-to-use, injectable, radiopaque, hydrophilic paste and uses the presence of moisture in dentinal tubules to initiate and complete its setting reaction, which range from $4 \mathrm{~h}$ to more than $10 \mathrm{~h}$ in very dry environment. ${ }^{[14]}$

Although several studies have addressed the removal of GP along with zinc oxide-eugenol and resin sealers, little is known regarding the removal of calcium silicate-based sealers from root canals. This is important taking into consideration the fact that these materials are known to be hard upon setting. ${ }^{[11]}$ The aim of this study was to evaluate the retreatability and reestablishment of apical patency of two calcium silicate-based sealers, MTA F and BCS when used for filling with GP, as compared with AH Plus (Dentsply DeTrey, Konstanz, Germany).

\section{METHODS}

\section{Sample preparation}

Human single-rooted anterior teeth $(n=54)$, extracted for periodontal reasons, were collected, cleaned using ultrasonics and stored in $0.5 \% \mathrm{NaOCl}$. The roots were decoronated at the cementoenamel junction using a diamond disk and water cooling. Only canals of $<20^{\circ}$ curvature and mature apices were included. The patency was confirmed by extending a size $10 \mathrm{~K}$-file (FKG Dentaire SA, La Chaux-de-Fonds, Switzerland) $1 \mathrm{~mm}$ past the anatomical apex and in the same manner the working length (WL) was established using the same $10 \mathrm{~K}$-file to the anatomical apex and subtracting $0.5 \mathrm{~mm}$ from this measurement. The root canal instrumentation was performed using WaveOne Primary (25/0.08) (Dentsply Maillefer, Ballaigues, Switzerland) nickel-titanium reciprocating instrument in an X-Smart Plus micromotor (Dentsply Maillefer, Ballaigues, Switzerland). Irrigation was performed using $5 \mathrm{~mL}$ of $5.25 \% \mathrm{NaOCl}$ with a $5 \mathrm{~mL}$ disposable plastic syringe (Ultradent Products Inc., South Jordan, UT) and a 30-G Endo-Eze tip (Ultradent). The removal of smear layer was performed by irrigating with $5 \mathrm{~mL}$ $17 \%$ ethylenediaminetetraacetic acid followed by $2 \mathrm{~mL}$ $5.25 \% \mathrm{NaOCl}$. All the irrigants were agitated with passive ultrasonic irrigation for $20 \mathrm{~s}$ using IrriSafe ultrasonic tip (Satelec Acteon, Mérignac, France). All the specimens were rinsed with $5 \mathrm{~mL}$ distilled water and dried with WaveOne Primary paper points (Dentsply Maillefer, Ballaigues, Switzerland). The patency was reconfirmed before filling with a \#10 K-file.

The roots were randomly divided into three groups $(n=18)$ to be filled with GP/AH Plus (Group A), GP/MTA F (Group B) or GP/BCS (Group C). These groups were further subdivided into two groups of nine specimens each, where in the first subgroup the master cone was placed to $\mathrm{WL}$ (Groups $\mathrm{A}_{\mathrm{L}^{\prime}} \mathrm{B}_{\mathrm{L}^{\prime}}$ and $\mathrm{C}_{\mathrm{L}}$ ) and in the second subgroup the master cone was trimmed to fit $2 \mathrm{~mm}$ short of the WL (Groups $\mathrm{A}_{\mathrm{S}^{\prime}} \mathrm{B}_{\mathrm{S}^{\prime}}$ and $\mathrm{C}_{\mathrm{S}}$ ) to simulate a short filling. WaveOne Primary (Dentsply Maillefer, Ballaigues, Switzerland) GP cones were used in all groups. The sealers were introduced into the root canal using a \#20 K-file (Flexofile, Dentsply Maillefer, Ballaigues, Switzerland) in order to coat the canal walls. The master GP cones were then coated with sealer and slowly inserted to the appropriate length. The continuous wave condensation was performed with the SuperEndo Alpha II and 55/0.08 heat plugger (B and L Biotech USA Inc., Philadelphia, USA) while the down-packing stopped $5 \mathrm{~mm}$ from the WL. All the orifices were sealed with a glass ionomer restorative material (Fuji IX GP FAST, GC Europe N.V, Leuven, Belgium). Subsequently, the quality of the filled roots was assessed with digital radiographs at different angulations. All the specimens were stored at $37^{\circ} \mathrm{C}$ in $100 \%$ humidity for 2 weeks. The same operator performed all endodontic procedures.

\section{Retreatment procedure}

For the retreatment, a piezoelectric ultrasonic device (P5 Newtron; Satelec Acteon, Mérignac, France) with an ultrasonic tip (BL1, B \& L Biotech USA Inc., Philadelphia, USA) was initially used in order to remove a superficial layer of GP and to create a small reservoir for the solvent. In this case, 2-3 drops of chloroform were introduced. WaveOne Large (40/0.08) (Dentsply Maillefer, Ballaigues, Switzerland) and Race 0.06 tapered NiTi rotary instruments were then inserted into the canal system at $600 \mathrm{rpm}$ according to the following technique: Race rotary instruments size 20 and 25 with 0.06 taper were used with pecking 
motions in a crown-down fashion and were advanced 2-3 mm into the canal system followed by flute clearing with alcohol gauze. This procedure was repeated until the WL was reached, or resistance was met. In cases, the WL was reached, patency was checked with 10 K-file and root canal instrumentation was continued using the Race rotary instruments with crown-down technique at $550 \mathrm{rpm}$ to the WL until size 30/0.06 was reached. WaveOne Large $(40 / 08)$ in reciprocating motion was finally used to WL as a finishing file. If the WL was not reached, small hand files $(C+$ Files sizes 6, 8, 10 and 15, Dentsply Maillefer) were used in order to penetrate and regain patency. When the WL was reached, the root canal instrumentation was continued as described above. In case the WL was not reached after all the attempts, the instrumentation was completed to the maximum length.

Copious amounts of $5.25 \% \mathrm{NaOCl}$ were used between each rotary file. The retreatment procedure was deemed complete when the aforementioned instrumentation procedure was completed to the full WL or to the maximum length reached. The ability to establish patency and reach WL was determined for each specimen. The time required to retreat each canal was also recorded.

\section{Dental optical microscope assessment}

The roots were scored coronoapically using a diamond disk and wedged apart. Specimens were observed under a dental, optical microscope (DOM) (Carl Zeiss OPMI Pro Ergo, Germany). The apical area and foramen were examined at $\times 10$ magnification and representative photos were taken.

\section{Statistical analysis}

Chi-square and Mann-Whitney U-test were applied to investigate potential differences within and between obturation material groups, as far as "WL regained," "patency establishment" and "time required" variables were concerned. However, for "WL regained" and "patency establishment" parameters no tests were computed, because all the recorded data for all the materials were identical. The analyzes of the data were carried out using IBM SPSS statistics software version 21.0 (SPSS, Inc., Chicago, IL, USA), with a 0.05 level of significance.

\section{RESULTS}

The WL was regained in $100 \%$ of specimens in all groups [Table 1]. The patency was reconfirmed in all specimens as well [Table 1]. No further statistical

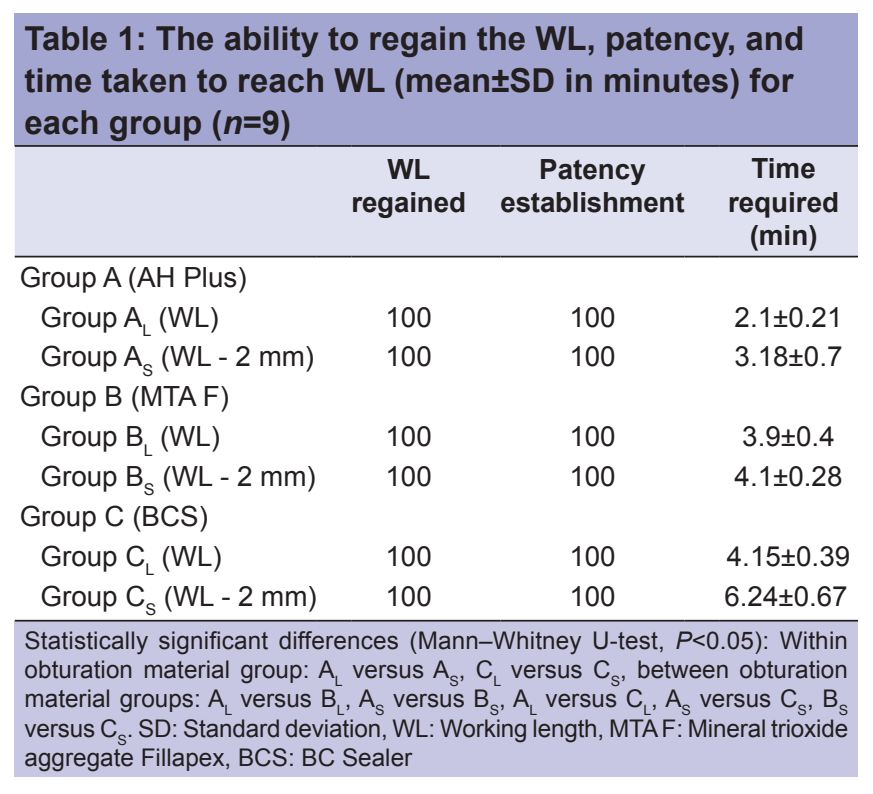

analysis was required. The mean time ( \pm standard deviation) required to reach the WL in each group is summarized in Table 1. Group Cs took the longest time to retreat followed by the groups $C_{L}, B_{S}, B_{L}, A_{S}$ and $A_{L}$. According to the statistical analysis, there were significant differences both between and within groups $(P<0.05)$. The Mann-Whitney U-test indicated significant differences between the following groups: $\mathrm{A}_{\mathrm{L}}$ versus $\mathrm{B}_{\mathrm{L}}(P=0.001), \mathrm{A}_{\mathrm{S}}$ versus $\mathrm{B}_{\mathrm{S}}(P<0.004), \mathrm{A}_{\mathrm{L}}$ versus $C_{L}(P=0.001)$, $A_{S}$ versus $C_{S}(P=0.001)$, and $B_{S}$ versus $C_{S}(P=0.001)$ [Table 1$]$. As far as it concerns within filling material groups, there was a significant difference between $A_{L}$ versus $A_{S}(P=0.001)$ and $C_{L}$ versus $C_{\mathrm{S}}(P=0.001)$.

DOM images of samples revealed filling material remaining in all groups. The most amount of remaining material can be observed in the groups of AH Plus [Figure 1a] while the least amount in the groups of MTA F [Figure 1b].

\section{DISCUSSION}

The purpose of this study was to evaluate the retreatability of two novel calcium silicate-based sealers namely MTA F and TotalFill BCS considering an epoxy resin sealer (AH Plus) as the standard for comparison. Based on the results of our study, obturation with the new sealers could not completely block the apical zone and patency was re-established in all samples.

Regarding the groups where the GP was seated at the $\mathrm{WL}$, the ability to re-establish the WL and patency can 


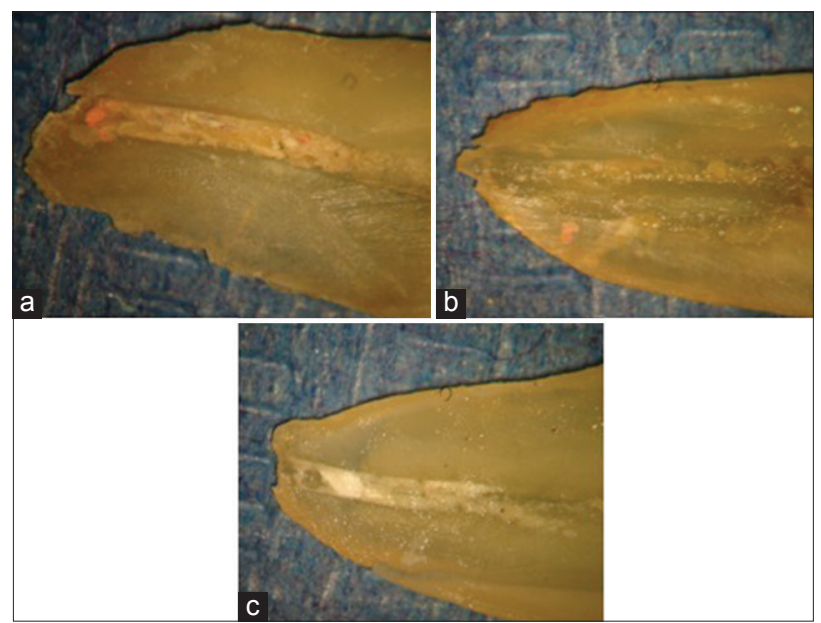

Figure 1: Representative photos of residual sealer in the apical canal space $(\times 10)$. (a) Group $A_{L}$ is showing AH Plus. (b) Group $B_{L}$ is showing mineral trioxide aggregate Fillapex. (c) Group $C_{L}$ showing BC Sealer

be attributed to the fully seated master cone. Although calcium silicate-based sealers become quite hard upon setting, ${ }^{[11]}$ the core material still remains GP. Many different solvents can be used for softening GP cones and other root canal filling materials. Chloroform is one of the most common solvents because it acts very rapidly, ${ }^{[15]}$ but it was also proposed to be a potential carcinogen. ${ }^{[16]}$ However, the current study was in vitro and hence, the chloroform was used. When the GP master cone is softened effectively, this may provide a pathway for the rotary and hand instruments to approach the apical foramen through the sealers.

In order to minimize the effect of GP on the ability to retreat the new sealers, the master cones were intentionally seated $2 \mathrm{~mm}$ short of the WL in three groups. Although these groups represent improper usage of filling materials, this may occur clinically. Even though there was no possible pathway to the apical foramen through the softened GP, WL, and patency were reconfirmed in $100 \%$ of samples. The results of our study regarding BCS come in contrast to Hess et al., who reported that patency was not reestablished in $70 \%$ of these samples. ${ }^{[17]}$ The retreatability of $100 \%$ of the samples in our study may be attributed to the differences in the root canal anatomy. While our samples were anterior teeth, Hess et al. used the mesiobuccal roots of mandibular molars. ${ }^{[17]}$ Anterior teeth have usually wide and straight canals while mesiobuccal roots of the mandibular molars exhibit a more complex anatomy. Regarding MTA F, the results of the present study are in agreement with Carpenter et al., implying that the chloroform may soften effectively the resin matrix of this sealer. ${ }^{[18]}$ This might be the reason behind the significant difference between $B_{S}$ and $C_{S}$ groups. It seems that chloroform solvents are not very effective regarding BCS removal. Further studies are required for the effect of different solvents and retreatment techniques on BCS and MTA F.

Furthermore, the average time required for removing calcium silicate-based sealers was longer than the time for AH Plus. According to the results, there were significant differences regarding retreatment time between $A_{L}$ versus $B_{L^{\prime}} A_{S}$ versus $B_{S^{\prime}} A_{L}$ versus $C_{L^{\prime}} A_{S}$ versus $C s$, and $B s$ versus $C_{S}$ groups. These results indicate clearly that calcium silicate-based sealers are more hard and resilient to common retreatment techniques but not impenetrable. Even if the theory of the possible pathway through the GP cone is true, the fact is that calcium silicate-based sealers increase retreatment time approximately twice in the case of BCS [Table 1]. Successful negotiation requires patience, more time and additional efforts in comparison with conventional filling materials. The time commitment for the retreatment required sometimes may compromise proper cleaning and shaping of the root canal system and affect the success of nonsurgical endodontic therapy.

Finally, quite interesting observations regarding the residual filling material could be made based on the pictures of the apical area under the DOM. None of the root filling materials could be completely removed. The most amount of remaining root filling material after the retreatment was observed with $\mathrm{AH}$ Plus [Figure 1a] followed by BCS [Figure 1b] and MTA F [Figure 1c]. These findings regarding MTA F are in agreement with the study of Neelakantan et al., who reported the low bond strength of MTA F to root dentin. ${ }^{[19]}$ A possible explanation for these findings may be the low adhesion capacity of MTA F reported in recent studies. ${ }^{[20]}$ Further investigations are required regarding the adhering properties of these new calcium silicate-based sealers and the ability to be retreated under different situations.

\section{CONCLUSIONS}

The present in vitro study suggests that the new calcium silicate-based sealers are negotiable, when the root canal anatomy is simple. However, these procedures may be time demanding. Under different root canal anatomies with much more complexity, the outcome might be quite different.

\section{Financial support and sponsorship}

Nil. 
Agrafioti, et al.: Retreatability of calcium silicate-based sealers

\section{Conflicts of interest}

There are no conflicts of interest.

\section{REFERENCES}

1. Mandel E, Friedman S. Endodontic retreatment: A rational approach to root canal reinstrumentation. J Endod 1992;18:565-9.

2. Hülsmann M, Bluhm V. Efficacy, cleaning ability and safety of different rotary NiTi instruments in root canal retreatment. Int Endod J 2004;37:468-76

3. Kratchman SI. Obturation of the root canal system. Dent Clin North Am 2004;48:203-15.

4. Tyagi S, Mishra P, Tyagi P. Evolution of root canal sealers: An insight story. Eur J Gen Dent 2013;2:199-218.

5. Koch K, Brave D. Bioceramic technology - The game changer in endodontics. Endod Pract 2009;2:13-7.

6. Salles LP, Gomes-Cornélio AL, Guimarães FC, Herrera BS, Bao SN, Rossa-Junior $\mathrm{C}$, et al. Mineral trioxide aggregate-based endodontic sealer stimulates hydroxyapatite nucleation in human osteoblast-like cell culture. J Endod 2012;38:971-6.

7. Gomes-Filho JE, Watanabe S, Bernabé PF, de Moraes Costa MT. A mineral trioxide aggregate sealer stimulated mineralization. J Endod 2009;35:256-60.

8. Huffman BP, Mai S, Pinna L, Weller RN, Primus CM, Gutmann JL, et al. Dislocation resistance of ProRoot Endo Sealer, a calcium silicate-based root canal sealer, from radicular dentine. Int Endod J 2009;42:34-46.

9. Morgental RD, Vier-Pelisser FV, Oliveira SD, Antunes FC, Cogo DM, Kopper PM. Antibacterial activity of two MTA-based root canal sealers. Int Endod J 2011;44:1128-33.

10. Zoufan K, Jiang J, Komabayashi T, Wang YH, Safavi KE, Zhu Q. Cytotoxicity evaluation of Gutta Flow and Endo Sequence BC sealers. Oral Surg Oral Med Oral Pathol Oral Radiol Endod 2011;112:657-61.

11. Kossev D, Stefanov V. Ceramics-based sealers as new alternative to currently used endodontic sealers. Roots 2009;1:42-8

12. Zhang H, Shen Y, Ruse ND, Haapasalo M. Antibacterial activity of endodontic sealers by modified direct contact test against Enterococcus faecalis. J Endod 2009;35:1051-5.

13. Available from: http://www.angelusdental.com/products/details/id/2 [Last accessed on 2015 Oct 10].

14. Available from: http://www.endoexperience.com/userfiles/file/ endo bcsealer.pdf. [Last accessed on 2015 Oct 10].

15. McDonald MN, Vire DE. Chloroform in the endodontic operatory. J Endod 1992;18:301-3.

16. FDA-United States Food and Drug Administration. Chloroform, Use as an Ingredient (active or inactive) in Drug Products. Federal Register Number: 26845. Washington DC: US Government Printing Office; 1976. p. $47-8$

17. Hess D, Solomon E, Spears R, He J. Retreatability of a bioceramic root canal sealing material. J Endod 2011;37:1547-9.

18. Carpenter MT, Sidow SJ, Lindsey KW, Chuang A, McPherson JC $3^{\text {rd }}$ Regaining apical patency after obturation with Gutta-percha and a sealer containing mineral trioxide aggregate. J Endod 2014;40:588-90.

19. Neelakantan P, Grotra D, Sharma S. Retreatability of 2 mineral trioxide aggregate-based root canal sealers: A cone-beam computed tomography analysis. J Endod 2013;39:893-6.

20. Assmann E, Scarparo RK, Böttcher DE, Grecca FS. Dentin bond strength of two mineral trioxide aggregate-based and one epoxy resin-based sealers. J Endod 2012;38:219-21.

\begin{tabular}{|l|l|}
\hline \multicolumn{3}{|c|}{ Access this article online } \\
\hline Quick Response Code: & \\
\hline
\end{tabular}

